\title{
A Cross-Cultural Comparison on Effects of eWOM Characteristics on Movie Sales Considering the Competitor
}

\author{
Jungwon Lee and Cheol Park \\ College of Global Business, Korea University
}

\begin{abstract}
Electronic word of mouth(eWOM) is communications among connected consumers on the Internet and becomes more reliable sources on products than marketing information. An eWOM plays a more important role in a competitive situation, because consumers are evaluating more than one alternative. Especially in the movie industry, online reviews by audiences play key roles in the financial performance of the movie. One of the main limitations of eWOM research is not to explain differences between cultures(Tang, 2017). The relationship between eWOM and firm performance has been verified by the product characteristics and review platform(You et al., 2015), but due to the complexity of language and expression, the cultural moderating effect has not been sufficiently explored(Tang, 2017). Recently, companies continue to be globalized, and marketing decisions to maximize eWOM effectiveness in other countries' cultures have become a big challenge for companies(Kumar et al., 2011). In this global environment, research that takes into account the negative effects of eWOM Characteristics of rival products is also limited. In this study, we analyzed the effect of eWOM characteristics on movie sales in competitive environment. We analyzed 10,371 data of 45 days from the opening of 252 movies released in Korea and US in 2017, 109 Korean movies were collected and 143 American movies were collected. Multiple regression analysis were conducted. As results, eWOM valence of rival movies had a negative effect on focal movie sales, and the effects of eWOM and competition factors were moderated by Korean and US cultural differences.
\end{abstract}

Keywords: eWOM, Culture, Valence, Variance, Korea, US, Movie, Online review Themes: Management, Marketing 
